\title{
A Coordinated Assessment between Green Finance and Ecological Environment along the Yangtze River Basin
}

\author{
Yu $\mathrm{Gan}^{1,3}$, Yichuan $\mathrm{Bu}^{2,4, *}$ \\ ${ }^{1}$ Finance and Insurance Department, Guangxi University of Finance and Economics, 530007 Nanning, China \\ ${ }^{2}$ Information Technology Department, Guangxi Finance Vocational College, 530007 Nanning, China \\ ${ }^{3}$ Graduate School of Business, SEGI University, 47810 Selangor, Malaysia \\ ${ }^{4}$ Education Department, SEGI University, 47810 Selangor, Malaysia
}

\begin{abstract}
Ecological environment is the basis for achieving sustainable development of an economy. As a financial innovation to support national economic development, green finance can rationally allocate and guide limited resources to the direction of environmental protection to the maximum extent. This paper introduces the coupled coordination model and takes the Yangtze River Basin as an example to measure the coupling relationship between green finance and ecological environment during 2003-2018. The main results show that: (1) The development level of green finance in the region is improving each year, but the overall foundation is still weak. (2) The level of the ecological environment has a stable and gradually improving trend. (3) The coupled coordination between the green financial system and eco-environmental system is gradually approaching the good coordination stage from the no coordinated stage. The coupling coordination index can reveal the overall characteristics of Yangtze River Basin and ensure regionally sustainable development.
\end{abstract}

\section{Introduction}

The Yangtze River (Fig.1), which is the third longest river in the world, runs east and west across China, covering fourteen provinces and cities, including Shanghai, Jiangsu, Anhui, Jiangxi, Henan, Hubei, Hunan, Chongqing, Sichuan, Guizhou, Gansu, Yunnan, Sichuan and Qinghai. The Yangtze River Basin accounts for about $20 \%$ of China's land mass and covers more than $40 \%$ of China's population ${ }^{[1]}$. And development over the last three decades has brought a certain amount of ecological damage to this area. In order to reduce the pressure on energy resources, China was pursuing a strategy of 'building a green financial system' to guide a sustainable and healthy economy.

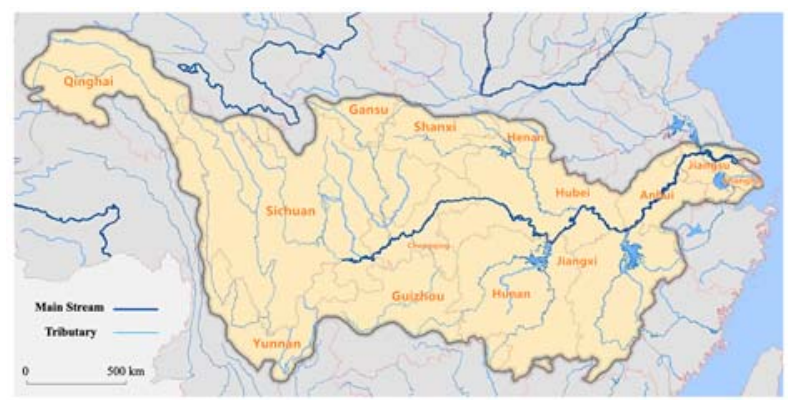

Fig. 1. Yangtze River Basin.
As a policy-oriented financial innovation, green finance links finance with the ecological environment. According to Wang, Y. and Zhi, Q. (2016) ${ }^{[2]}$, green finance is a phenomenon that combines the world of finance and business with environmentally friendly behavior. Throughout the existing literature, most of the analysis is based on the economic and environmental benefits of green finance ${ }^{[2-4]}$. There is a lack of quantitative measurement of green finance and its dynamic relationship with ecological environment. Therefore, this paper aims to establish a coupled coordination model of green finance and ecological environment based on the current environmental conditions along the Yangtze River basin, in order to demonstrate the improvement and to provide a scientific basis for future sustainable development.

\section{Materials and methods}

\subsection{Developing Indicators and Weighting Methods}

In this study, the provinces and cities surrounding the Yangtze River basin are taken as the research population, and the data selection interval is from 2003-2018. Since most of the selected indicators possess different units and formats, we first converted all the instruments into the same format and classified the range values. The

\footnotetext{
*Corresponding author: dukebu@qq.com
} 
subsequent procedure is used following the study of Junhan, L. and Mingxiu, G. (2018) ${ }^{[5]}$.

The first step is to normalize the selected data.

For the data which is positive:

$$
Y_{i j}=\frac{X_{i j}-\min \left(X_{i j}\right)}{\max \left(X_{i j}\right)-\min \left(X_{i j}\right)}
$$

For the data which is negative:

$$
Y_{i j}=\frac{\max \left(X_{i j}\right)-X_{i j}}{\max \left(X_{i j}\right)-\min \left(X_{i j}\right)}
$$

where $Y_{i j}$ represents the normalized value of a variable, $X_{i j}$ is the value of the $j_{t h}$ indicator of the $i_{t h}$ scheme. The values of all indicators were normalized into $[0,1]$.

Further, the entropy value method would be applied to determine the weight of model indicators to avoid the influence of subjective assignment method on the evaluation results.

$$
E_{i}=-k \sum_{j=1}^{n}\left(p_{i j} \times \ln p_{i j}\right)
$$

Where $E_{i}$ represents the entropy value of the $i_{t h}$ indicator of each subsystem. And

$$
K=\frac{1}{l n m}, p_{i j}=\frac{Y_{i j}}{\sum_{j=1}^{n} Y_{i j}} \quad(i=1,2, \ldots m ; j=1,2, \ldots n)
$$

The next step is to calculate the weights of the indicators.

$$
W_{i}=\frac{1-E_{i}}{m-\sum_{i=1}^{m} E_{i}} \quad(i=1,2, \ldots n)
$$

Where $W_{i}$ represents the indicator weight of each subsystem.

\subsection{Coupling Coordination Degree Model}

Coordination reflects the degree of coherence between all subsystems, as well as the extent to which the system tends to be ordered ${ }^{[6]}$.

The coupling calculation degree model is given as following equation:

$$
C=\frac{\sqrt{U_{1} \times U_{2}}}{U_{1}+U_{2}}
$$

where $\mathrm{C}$ is the degree of coupling between green finance and ecological systems, with values ranging into $[0,1] . U_{1}$ and $U_{2}$ indicate the level of of green finance and the integrated eco-environmental values. And

$$
U_{i}=\sum_{j=1}^{n} W_{j} S_{i j}
$$

Where $W_{j}$ represents the indicator weight of each subsystem, $S_{i j}$ indicates the standardized value of $j_{t h}$ indicator in $i_{t h}$ year.

Therefore, the coupling coordination model can be further constructed after obtaining the coupling degree between systems.

$$
D=\sqrt{C \times T}, T=\alpha U_{1}+\beta U_{2}
$$

Where $\mathrm{D}$ is the coordination degree, $\mathrm{C}$ represents the coupling degree; $\mathrm{T}$ indicates the comprehensive evaluation index of two systems. $\alpha$ and $\beta$ represent the contribution of green finance and ecological environment, respectively. In order to more accurately determine the coupled coordination between two systems, a uniform distribution function was used to classify the degree of coordination (Table 1).

Table 1 Classification of Coupling Coordination Degree

\begin{tabular}{cc}
\hline D Value Interval & Coordination Types \\
\hline $0.00-0.20$ & No Coordination (NC) \\
$0.21-0.40$ & Little Coordination (LC) \\
$0.41-0.60$ & Basic Coordination (BC) \\
$0.61-0.80$ & Good Coordination (GC) \\
$0.81-1.00$ & Excellent Coordination (EC) \\
\hline
\end{tabular}

\section{Result and Findings}

\subsection{System Construction}

To ensure the validity of measurement, this paper divides the green financial system into three primary indicators and four secondary indicators, and the eco-environmental system was divided into four primary indicators and thirteen secondary indicators to represent the development level of green finance and eco-environment, respectively. All data of indicators

\begin{tabular}{|c|c|c|c|c|c|}
\hline System & Subsystem & Weight & Evaluation Index & Nature & Weight \\
\hline \multirow{4}{*}{$\begin{array}{c}\text { Green } \\
\text { Financial } \\
\text { Development } \\
\text { System }\end{array}$} & Green Credit & 0.36 & $\begin{array}{l}\text { Loan Volume of Green } \\
\text { Credit Project as } \\
\text { Percentage of Total } \\
\text { Loans (\%) }\end{array}$ & + & 0.36 \\
\hline & \multirow[t]{2}{*}{ Green Investment } & \multirow[t]{2}{*}{0.25} & $\begin{array}{l}\text { Investment of Anti- } \\
\text { pollution Project as } \\
\text { Percentage of GDP (\%) }\end{array}$ & + & 0.12 \\
\hline & & & $\begin{array}{l}\text { Forestry Investment } \\
\text { (10,000 yuan) }\end{array}$ & + & 0.13 \\
\hline & $\begin{array}{l}\text { Green Factory } \\
\text { Development }\end{array}$ & 0.39 & $\begin{array}{l}\text { Number of Green } \\
\text { Factories and Zone }\end{array}$ & + & 0.39 \\
\hline \multirow{13}{*}{$\begin{array}{l}\text { Ecological } \\
\text { Environment } \\
\text { al System }\end{array}$} & & & Temperature $\left({ }^{\circ} \mathrm{C}\right)$ & - & 0.05 \\
\hline & Hydrometeorology & 0.09 & $\begin{array}{l}\text { Water Quality in } \\
\text { Yangtze River (level) }\end{array}$ & $\cdot$ & 0.04 \\
\hline & \multirow{5}{*}{ Socioeconomics } & \multirow{5}{*}{0.39} & $\begin{array}{l}\text { Carbon emissions }(1 \\
\left.\text { thousands tons of } \mathrm{CO}_{2}\right)\end{array}$ & $\cdot$ & 0.08 \\
\hline & & & $\begin{array}{l}\text { Waste Water Discharged } \\
\text { (1billion tons) }\end{array}$ & $\cdot$ & 0.06 \\
\hline & & & $\begin{array}{c}\text { Sulphur Dioxide } \\
\text { Emissions ( } 10,000 \text { tons })\end{array}$ & $\cdot$ & 0.11 \\
\hline & & & $\begin{array}{l}\text { Solid Waste Discharged } \\
\text { (10,000 tons) }\end{array}$ & - & 0.08 \\
\hline & & & $\begin{array}{l}\text { Total Consumption of } \\
\text { Energy (10000 tons) }\end{array}$ & $\cdot$ & 0.06 \\
\hline & \multirow{4}{*}{$\begin{array}{l}\text { Environmental } \\
\text { Governance }\end{array}$} & \multirow{4}{*}{0.27} & $\begin{array}{l}\text { Wastewater Treatment } \\
\text { Capacity (10,000 } \\
\text { tons/day) }\end{array}$ & + & 0.05 \\
\hline & & & $\begin{array}{l}\text { Rate of Industrial Solid } \\
\text { Wastes } \\
\text { Comprehensively } \\
\text { Utilized (\%) }\end{array}$ & + & 0.07 \\
\hline & & & $\begin{array}{c}\text { Waste Gas Treatment } \\
\text { Capacity }(10,000 \\
\left.m^{3} \text { hour }\right)\end{array}$ & + & 0.11 \\
\hline & & & $\begin{array}{l}\text { Houschold Waste } \\
\text { Disposal Rate (\%) }\end{array}$ & + & 0.04 \\
\hline & \multirow{2}{*}{$\begin{array}{l}\text { Ecological } \\
\text { Protection }\end{array}$} & \multirow{2}{*}{0.25} & $\begin{array}{l}\text { Forest Coverage Rate } \\
(\%)\end{array}$ & + & 0.11 \\
\hline & & & $\begin{array}{c}\text { Area of Nature Reserves } \\
(10,000 \text { hectares })\end{array}$ & + & 0.14 \\
\hline
\end{tabular}
were collected from 2003-2019 China Statistical Yearbook, China Environmental Statistical Yearbook, Statistical Yearbook of provinces and Corporate Social Responsibility Report of Banks. The indicator evaluation system was shown in Table 2.

Table 2. Indicator Evaluation System of Green Finance and Ecological Environment.

\subsubsection{Dimensions of Green financial System}

The green financial system consists of three dimensions and four secondary indicators. Since green finance is still in the initial stage of development in China, it is relatively challenging to construct an indicator system. This paper tries to build a multi-dimensional and comprehensive system that contains reasonable 
indicators. Therefore, it is necessary to emphasize the selection methods and classification criteria of existing literatures.

Hong, L. et al (2019) ${ }^{[7]}$ takes green credit, green securities, green investment and carbon finance projects into account when evaluating the development level of green finance in China. While Jun, J. (2018) ${ }^{[8]}$ conducts the evaluation of the green financial system for setting the primary indicator to green financial efficiency, measured by three secondary indicators, such as forestry investment, fixed asset investment and green credit. However, as this paper addresses a regional assessment, some of the data cannot be clearly disaggregated. Therefore, this paper takes the three dimensions of green credit, green investment and green factory development as a starting point, and selects four indicators which can be seen from Table 2 .

\subsubsection{Dimensions of Eco-environmental System}

The eco-environmental system consists of four dimensions and thirteen secondary indicators. The regional eco-efficiency level is conditioned by factors such as geographical location and environmental policies. According to Shen, H. et al., (2015) ${ }^{[9]}$, a system of indicators such as environmental efficiency, resource and energy consumption, and circular economy can be used to evaluate the ecological efficiency of the Yangtze River Basin. And K. A., and Liou, Y. A. (2019) ${ }^{[10]}$ summarized an indicator system that used to estimate global eco-environmental vulnerability. However, while considering the commonality, we also need to construct the indicators according to the current ecological and environmental protection situation. Only in this way will this indicator system have practical significance.

Thus, in this paper, the corresponding indicators are selected from the four dimensions of hydrometeorology, socioeconomics, environmental governance and ecological protection to reflect the actual level of eco-environmental system. Among them, as shown in Table 2, the socioeconomics dimension contains the greatest number of indicators and has the highest weight. This is due to the fact that sources of pollution such as wastewater discharge and Sulphur dioxide have a directly negative impact on the quality of the ecosystem.

\subsection{Development Level of Green finance}

In order to visualize the trend of green financial development in the Yangtze River Basin, this paper draws line graphs for comparison. Figure 2 shows the tendency of green financial development in 14 provinces and cities since 2003. It can be seen that the overall direction of green finance is gradually improving. However, in both 2009 and 2018, the values in some areas have decreased. In 2009, the development of green finance was severely hit by the financial crisis, and policies on investment and financing were all revised. In 2014-2018, the expansion of green finance accelerated rapidly in all areas. However, due to an adjustment to the green financial system, the value of some regions declined in 2018, but overall green finance has still gained fairly rapid development in China.

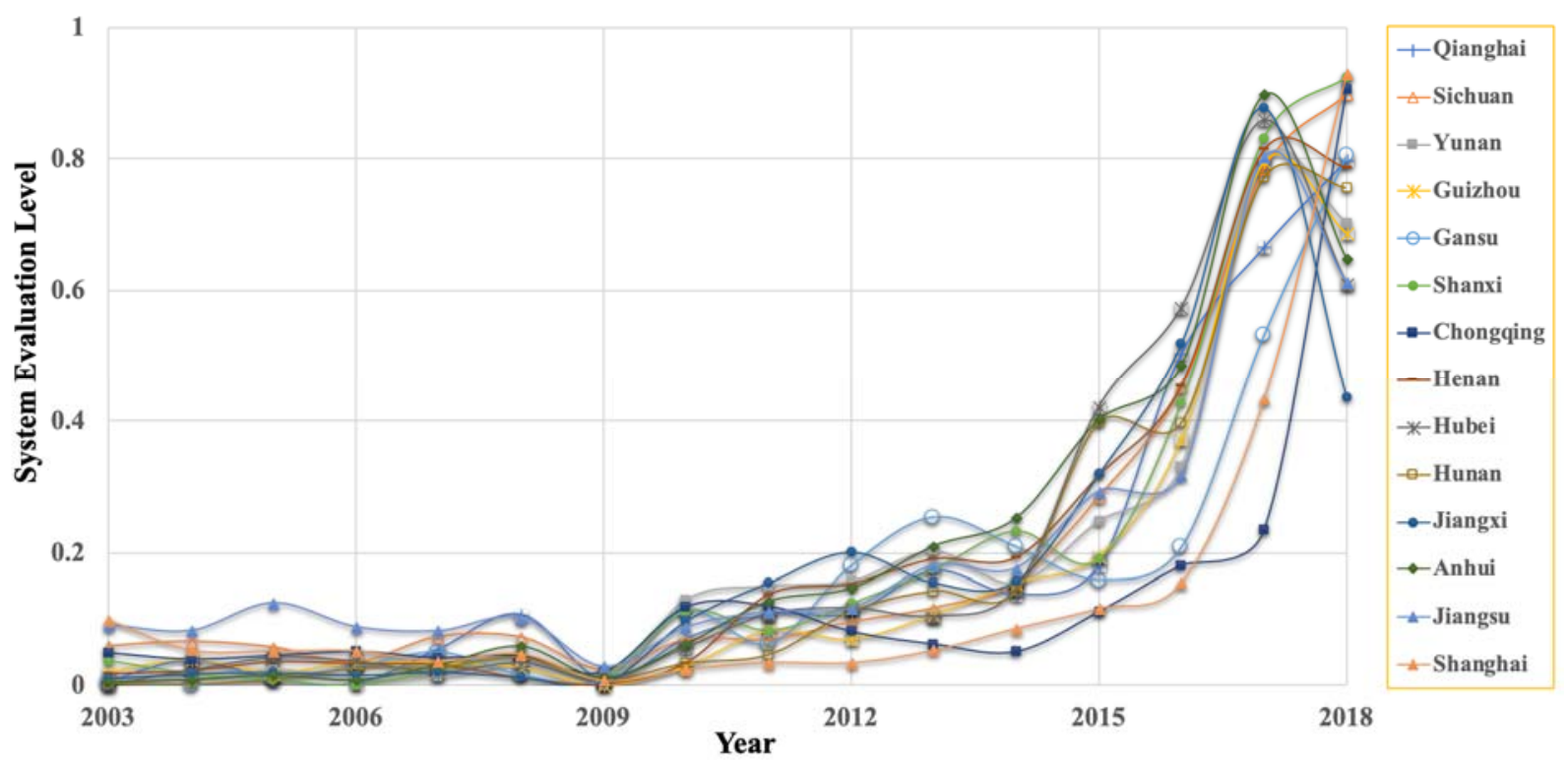

Fig. 2. Trends in Green Financial System.

\subsection{Development Level of Eco-environment}

Following the mechanisms of the green financial system, a line graph (Figure 3) also be drawn to express the trends of the eco-efficiency system. From Figure 3, it can be seen that the ecological environment of the Yangtze River Basin is generally more stable. In terms of the results, which are similar to the green financial system, the eco-efficiency score declined in 2009. It mainly due to the outbreak of the US financial crisis in 2008 and China's reaction to the crash, which in turn had a certain negative impact on the environment. Subsequently, Shanghai, Hunan and Jiangsu were found to have significantly improved their ecological environment over the 2014-2018 interval. Beyond that, the rest of the 
regions and the years have been relatively steady.

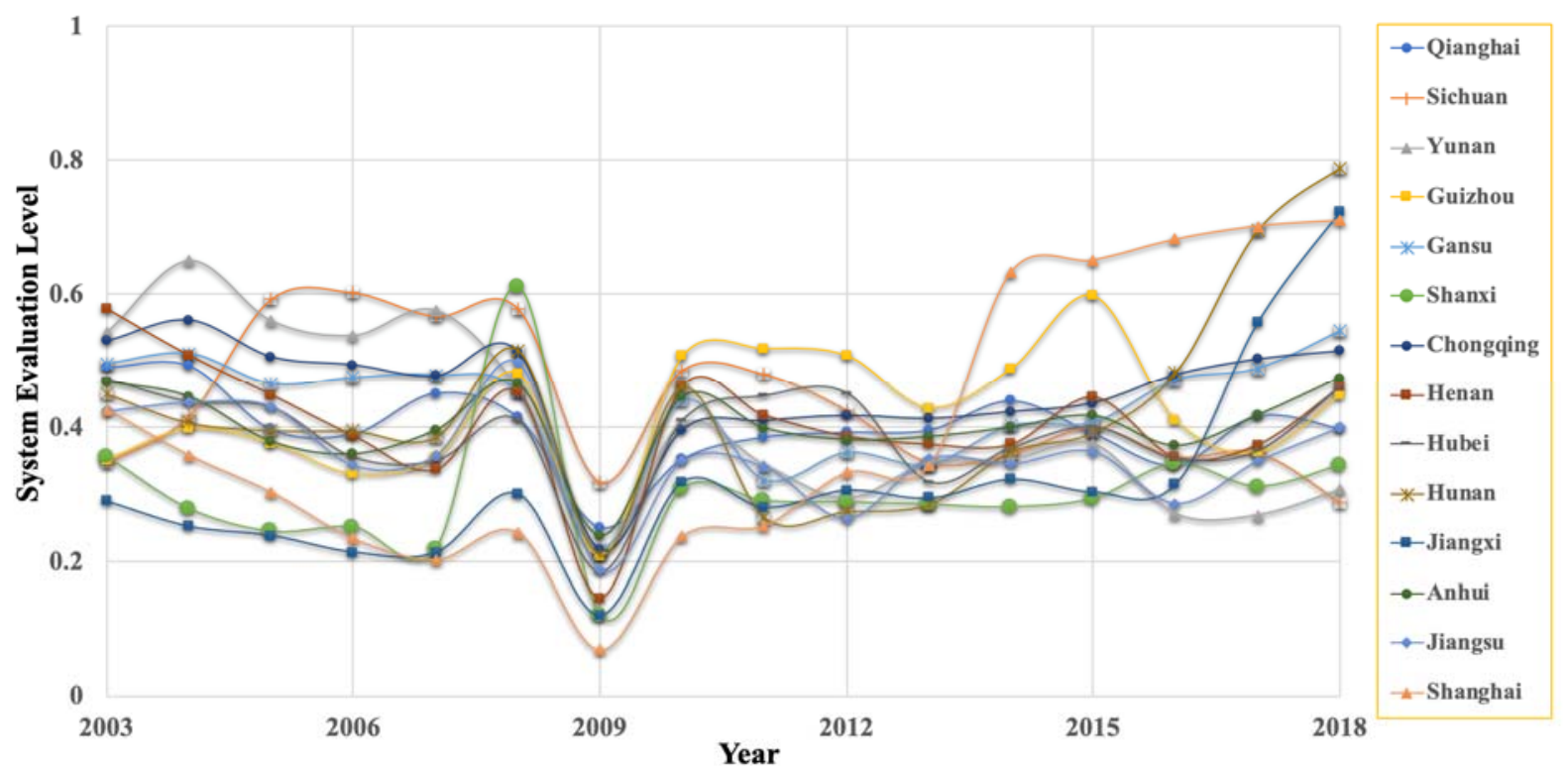

Fig. 3. Trends in Eco-environment System.

\subsection{Coupling and Coordination Analysis}

According to Equations (5)-(7), this paper calculates the coupled coordination of Green Financial system and Eco-environmental System. From Table 3, it can be seen that until the year 2010, the Yangtze River Basin were mostly in the state of no coordination (NC). Initially, green investments did not result in a significant improvement of the ecological environment. Starting in the year 2011, there seems to have been a turnaround, enabling green finance and ecology to become harmonized. From the perspective of coupling coordination, the values from 2011 to 2015 is in the stage of little coupling and coordination. After year 2016, the trend gradually accelerated. And by 2018, a few regions were already in the stage of good coordination (GC), and Shanghai had already jumped into EC state.

In terms of results, the full synergistic development of green finance and ecology in the Yangtze River Basin will take longer to practice. However, in the meantime, it also can be found that since China explicitly proposed the policy of green finance in 2014, its coupling coordination value with the ecological environment has rapidly increase.

Therefore, in the pursuit of coupled coordination between green finance and regional ecological environment, it is necessary to implement financial resources to truly support 'green' industries, and to reduce the pollution by traditional industries, to improve the digestibility and utilization efficiency of new energy. Thus, improving each subsystems of the coordinated development.

Table 3. The Coordination Types of Yangtze River Basin, 2003-2018

\begin{tabular}{|c|c|c|c|c|c|c|c|c|c|c|c|c|c|c|c|c|}
\hline Year & 2003 & 2004 & 2005 & 2006 & 2007 & 2008 & 2009 & 2010 & 2011 & 2012 & 2013 & 2014 & 2015 & 2016 & 2017 & 2018 \\
\hline Qianghai & $\mathrm{NC}$ & $\mathrm{NC}$ & $\mathrm{NC}$ & $\mathrm{NC}$ & $\mathrm{NC}$ & LC & $\mathrm{NC}$ & $\mathrm{NC}$ & LC & LC & LC & LC & LC & BC & BC & BC \\
\hline Sichuan & $\mathrm{NC}$ & $\mathrm{NC}$ & $\mathrm{NC}$ & $\mathrm{NC}$ & LC & LC & $\mathrm{NC}$ & $\mathrm{NC}$ & $\mathrm{NC}$ & LC & LC & LC & LC & BC & BC & $\mathrm{BC}$ \\
\hline Yunan & $\mathrm{NC}$ & $\mathrm{NC}$ & $\mathrm{NC}$ & $\mathrm{NC}$ & $\mathrm{NC}$ & $\mathrm{NC}$ & $\mathrm{NC}$ & LC & LC & LC & LC & LC & LC & LC & BC & BC \\
\hline Guizhou & NC & $\mathrm{NC}$ & $\mathrm{NC}$ & $\mathrm{NC}$ & $\mathrm{NC}$ & NC & NC & NC & LC & $\mathrm{NC}$ & LC & LC & LC & LC & $\mathrm{BC}$ & BC \\
\hline Gansu & $\mathrm{NC}$ & $\mathrm{NC}$ & $\mathrm{NC}$ & $\mathrm{NC}$ & $\mathrm{NC}$ & $\mathrm{NC}$ & $\mathrm{NC}$ & LC & $\mathrm{NC}$ & LC & LC & LC & LC & LC & BC & GC \\
\hline Shanxi & $\mathrm{NC}$ & $\mathrm{NC}$ & $\mathrm{NC}$ & $\mathrm{NC}$ & $\mathrm{NC}$ & $\mathrm{NC}$ & $\mathrm{NC}$ & NC & $\mathrm{NC}$ & $\mathrm{NC}$ & LC & LC & LC & LC & BC & BC \\
\hline Chongqing & $\mathrm{NC}$ & $\mathrm{NC}$ & $\mathrm{NC}$ & NC & $\mathrm{NC}$ & NC & $\mathrm{NC}$ & LC & LC & NC & NC & $\mathrm{NC}$ & LC & LC & LC & GC \\
\hline Henan & $\mathrm{NC}$ & $\mathrm{NC}$ & $\mathrm{NC}$ & $\mathrm{NC}$ & $\mathrm{NC}$ & $\mathrm{NC}$ & $\mathrm{NC}$ & $\mathrm{NC}$ & LC & LC & LC & LC & LC & BC & BC & GC \\
\hline Hubei & $\mathrm{NC}$ & $\mathrm{NC}$ & $\mathrm{NC}$ & $\mathrm{NC}$ & $\mathrm{NC}$ & $\mathrm{NC}$ & $\mathrm{NC}$ & $\mathrm{NC}$ & LC & LC & NC & LC & BC & BC & BC & BC \\
\hline Hunan & $\mathrm{NC}$ & $\mathrm{NC}$ & NC & $\mathrm{NC}$ & $\mathrm{NC}$ & $\mathrm{NC}$ & $\mathrm{NC}$ & $\mathrm{NC}$ & NC & $\mathrm{NC}$ & LC & LC & LC & $\mathrm{BC}$ & GC & GC \\
\hline Jiangxi & NC & $\mathrm{NC}$ & NC & $\mathrm{NC}$ & $\mathrm{NC}$ & $\mathrm{NC}$ & $\mathrm{NC}$ & NC & LC & LC & LC & LC & LC & BC & GC & BC \\
\hline Anhui & $\mathrm{NC}$ & NC & $\mathrm{NC}$ & $\mathrm{NC}$ & $\mathrm{NC}$ & $\mathrm{NC}$ & $\mathrm{NC}$ & NC & LC & LC & LC & LC & $\mathrm{BC}$ & $\mathrm{BC}$ & GC & $\mathrm{BC}$ \\
\hline Jiangsu & NC & $\mathrm{NC}$ & LC & $\mathrm{NC}$ & $\mathrm{NC}$ & LC & NC & NC & NC & NC & LC & LC & LC & LC & BC & BC \\
\hline Shanghai & LC & $\mathrm{NC}$ & $\mathrm{NC}$ & $\mathrm{NC}$ & $\mathrm{NC}$ & $\mathrm{NC}$ & NC & $\mathrm{NC}$ & $\mathrm{NC}$ & NC & $\mathrm{NC}$ & LC & LC & LC & $\mathrm{BC}$ & EC \\
\hline
\end{tabular}

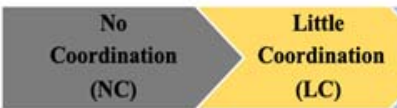

LOW LEVEL 


\section{Conclusion}

In this study, it is shown that coupled coordination models can be a useful tool to quantitatively analyze the linkages between green financial system and ecosystem.

By applying the coupled coordination model to measure the level of development of green finance and ecological environment in the Yangtze River Basin, it can be found that the type of coupled coordination has evolved from year 2003 to 2018 through no coordination to good coordination, even excellent coordination. And from the current stage of coupled coordination in the provinces/cities of the Yangtze River Basin, it is clear that the scale of green finance in China has yet to be improved, and the completely synergistic development of green finance and ecological environment will take a further period of time.

\section{Acknowledge}

The authors would like to extend sincere appreciation to Guangxi University of Finance and Economics for providing research funding. This research is supported by the Young Teachers Research Supporting Fund of Guangxi (2019KY0649 and 2019KY0653).

\section{References}

1. Yang, H. F., Yang, S. L., Xu, K. H., Milliman, J. D., Wang, H., Yang, Z., ... \& Zhang, C. Y. (2018). Human impacts on sediment in the Yangtze River: A review and new perspectives. Global and Planetary Change, 162, 8-17.

2. Wang, Y., Zhi, Q. (2016). The role of green finance in environmental protection: Two aspects of market mechanism and policies. Energy Procedia, 104, 311-316.

3. Zhang, D., Zhang, Z., \& Managi, S. (2019). A bibliometric analysis on green finance: Current status, development, and future directions. Finance Research Letters, 29, 425-430.

4. Sachs, J., Woo, W. T., Yoshino, N., \& Taghizadeh-Hesary, F. (2019). Importance of green finance for achieving sustainable development goals and energy security. Handbook of Green Finance: Energy Security and Sustainable Development, 3-12.

5. Junhan, L., \& Mingxiu, G. (2018). Spatial-temporal differentiation and coupling coordination degree of eco-efficiency and resource environmental bearing capacity in Shandong Province. Ecological Economy, 34(10), 61-68.

6. Mamat, Z., Yimit, H., Eziz, M., \& Ablimit, A. (2013). Analysis of the ecology-economy coordination degree in Yanqi Basin, Xinjiang, China. Asian Journal of Chemistry, 25(16), 9034.

7. Hong, L., Yingchao, Y., \& Na, W. (2019). Evaluation of the coordinated development of regional green finance and ecology. Statistics and Decision Making, 524, 161-164.

8. Jun, J. (2018). A research on ecosystems and green finance based on two major urban agglomerations. Contemporary economy, 12, 56-58.

9. Shen, H., Gao, C., He, D., \& Wu, L. (2015). New biometrics-based authentication scheme for multi-server environment in critical systems. Journal of Ambient Intelligence and Humanized Computing, 6(6), 825-834.

10. Nguyen, K. A., \& Liou, Y. A. (2019). Global mapping of eco-environmental vulnerability from human and nature disturbances. Science of The Total Environment, 664, 995-1004. 